\title{
Perancangan Prototype Alat Pemilah Sampah Otomatis
}

\author{
Faisal Irsan Pasaribu, Marcopolo \\ Program Studi Teknik Elektro, Fakultas Teknik \\ Universitas Muhammadiyah Sumatera Utara (UMSU) \\ Jl. Kapten Muchtar Basri,BA No. 03 Medan Telp. (061) 6622400 ex. 12 Kode pos 20238 \\ e-mail: faisalirsan@umsu.co.id
}

\begin{abstract}
Abstrak - Jumlah sampah yang berlebihan dapat diatasi dengan cara daur ulang. Sebelum melakukan daur ulang, limbah harus disortir terlebih dahulu. Pemilahan sampah secara otomatis dalam jumlah besar dapat dilakukan dengan menggunakan sensor infra merah, sensor logam, dan sensor cahaya. Hasil pengujian menunjukkan bahwa pemilahan sampah otomatis dapat memilah sampah sesuai jenisnya. Namun masih ada kesalahan berupa limbah yang macet dan deteksi kesalahan oleh sensor.
\end{abstract}

Kata kunci : Pemisahan Limbah Otomatis, Sensor.

Abstract - The amount of waste excessive can be overcome by way of recycling. Before do recycling, the waste must be sorted first. Sorting waste automatically in a huge amount can be done by using infra red sensor, metal sensor, and light sensor. The result of test show that the automatic waste sorting have been able to sort waste according to its kind. But still there are errors in the form of waste that stuck and the error detection by sensors.

Keywords : $\quad$ Automatic Waste Separation, Sensor.

\section{PENDAHULUAN}

Manusia membutuhkan banyak benda untuk menunjang proses kegiatan yang dilakukan. Penggunaan benda akan mengurangi dan membuat nilai gunanya menjadi habis. Benda yang telah kehilangan nilai guna dan tidak dapat digunakan lagi akan dikategorikan sebagai sampah. Meningkatnya jumlah pertumbuhan populasi manusia berbanding lurus dengan peningkatan jumlah sampah. Sampah yang berlebihan membuat tempat penampungan sampah melewati batas tampung hingga meluap ke tempat lain. Dengan adanya jumlah sampah yang berlebihan, akan menyebabkan banyak efek buruk yang dapat mempengaruhi lingkungan maupun manusia. Kesehatan dan kebersihan akan terganggu akibat timbulnya bibit penyakit yang bersumber dari jumlah sampah berlebihan.

Oleh sebab tersebut, maka masalah kelebihan jumlah sampah tidak dapat teratasi dengan menerapkan metode pemilahan manual. Untuk mengatasi masalah tersebut, telah dirancang alat untuk dapat memisahkan jenis sampah. Pemilahan sampah dapat dilakukan dengan cara menghancurkan sampah terlebih dahulu, dengan tujuan agar sampah lebih mudah terpisah [1]. Selain metode memilah sampah dengan menghancurkan sampah, terdapat metode lain yakni dengan memanfaatkan sensor untuk membedakan jenis sampah [2]. Berdasarkan pada hal tersebut, maka dapat disimpulkan bahwa masih dibutuhkan sistem dan alat yang mampu membedakan jenis sampah agar pemilahan dapat berjalan lebih efektif. Pada penelitian ini, akan dibahas tentang alat yang mampu memisahkan jenis sampah tersebut dengan cara membedakan jenis bahan sampah secara otomatis.

\section{TINJAUAN PUSTAKA}

\section{A. Arduino}

Arduino adalah sebuah produk design system minimum mikrokontroler yang di buka secara bebas. arduino menggunakan bahasa pemrograman $\mathrm{C}$ yang telah dimodifikasi dan sudah ditanamkan program bootloader yang berfungsi untuk menjembatani antara software compiler arduino dengan mikrokontroler. Untuk koneksi dengan komputer menggunakan RS232 to TTL Converter atau menggunakan Chip USB ke serial converter seperti FTDI FT232 [4].

\section{B. Arduino Uno}

Arduino uno adalah papan kontroler yang berdasarkan pada mikrokontroler ATmega328 [6]. Arduino uno memiliki 14 pin digital input/output. Arduino uno (Gambar 1) terdiri dari 6 pin yang dapat digunakan sebagai output $P W M, 6$ input analog, sebuah resonator keramik $16 \mathrm{MHz}$, koneksi USB, jack power, header ICSP, dan tombol reset. Arduino uno memuat semua yang dibutuhkan untuk mendukung mikrokontroler dan mudah menghubungkannya ke sebuah komputer dengan menguunakan kabel USB atau mensuplainya dengan sebuah adaptor $A C-D C$ atau menggunakan baterai untuk memulainya [5]. 


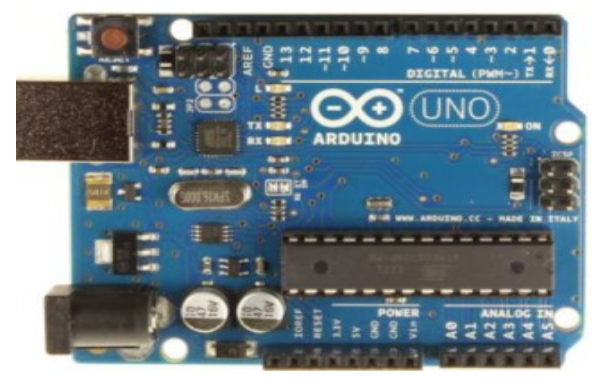

Gambar 1. Arduino Uno [1]

\section{Sensor}

Sensor adalah alat untuk mendeteksi/mengukur suatu besaran fisis berupa variasi mekanis, magnetis, panas, sinar dan kimia dengan diubah menjadi tegangan dan arus listrik. Sensor itu sendiri terdiri dari transduser dengan atau tanpa penguat/pengolah sinyal yang terbentuk dalam satu sistem pengindera. Dalam lingkungan sistem pengendali dan robotika, sensor memberikan kesamaan yang menyerupai mata, pendengaran, hidung, lidah yang kemudian akan diolah oleh kontroler sebagai otaknya [8].

1. Modul Sensor Jarak Infra Merah (IR) FC-51

Merupakan modul sensor yang digunakan untuk mendeteksi jarak dari suatu benda. Menggunakan IC LM 393 sebagai komparator serta mampu mendeteksi objek dengan rentang jarak 2-30 cm.

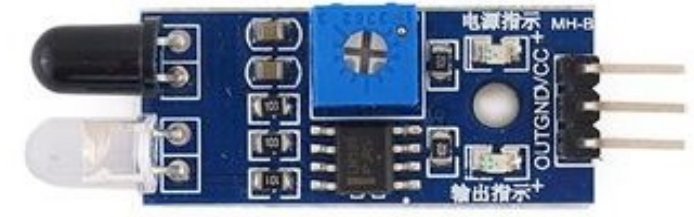

Gambar 2. Modul Sensor Jarak Infrared (FC-51) [4]

Spesifikasi sensor infra red FC51 meliputi [9].:
a. Jarak deteksi : $2 \mathrm{~cm}$ hingga
$30 \mathrm{~cm}$
b. Sudut deteksi : 35 derajat
c. Chip komparator : LM393
d. Tegangan kerja : $3-5 \mathrm{~V} D C$.
e. Ukuran papan : $3,2 \times 1,4 \mathrm{~cm}$.

\section{LED IR (Infra Red)}

Transceiver adalah komponen elektronika yang bersifat memancarkan sinyal, sedangkan receiver adalah komponen elektronika yang bersifat menerima sinyal. Komponen ini memiliki prinsip kerja seperti LED (Light Emitting Diode), hanya saja yang dipancarkan adalah sinar infra merah yang tidak tampak oleh mata. Intensitas cahaya yang melaluinya sebanding dengan arus yang melewatinya, tetapi arus yang melaluinya tidak lebih dari $50 \mathrm{~mA}$. Komponen ini juga seperti $L E D$, namun pancaran sinarnya sejajar dan bisa mencapai jarak yang cukup jauh. $L E D$ infra merah merupakan komponen elektronika yang memancarkan cahaya infra merah dengan konsumsi daya sangat kecil. Pada saat menghantar, LED infra merah memancarkan cahaya yang tidak tampak oleh mata. LED infra merah mengeluarkan panjang gelombang sekitar 0,9 mikrometer [10].

Rangkaian Dasar Pengoperasian LED infra merah dapat dilihat pada gambar berikut ini.

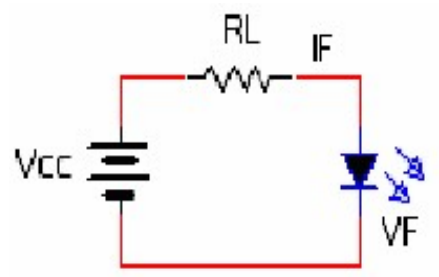

Gambar 3. Rangkaian Dasar Pengoperasian LED Infra Merah [5]

$$
\mathrm{R}_{\mathrm{L}}=\quad \frac{V c c-V f}{I f}
$$

Keterangan:

$$
\begin{array}{ll}
\mathrm{R}_{\mathrm{L}} & =\text { Hambatan pada resistor }(\Omega) \\
\mathrm{V}_{\mathrm{CC}} & =\text { Sumber tegangan DC }(\mathrm{V}) \\
\mathrm{V}_{\mathrm{f}} & =\text { Tegangan pada LED IR }(\mathrm{V}) \\
\mathrm{I}_{\mathrm{f}} & =\text { Kuat arus pada LED IR }(\mathrm{A})
\end{array}
$$

\section{IC LM393}

LM393 adalah sebuah IC (Integrated Circuit) yang berfungsi sebagai pembanding tegangan (Voltage Comparator). IC (Integrated Circuit) ini dapat diaplikasikan pada berbagai perangkat elektronik, diantaranya digunakan dalam rangkaian pengisi baterai (Batteray Charger), Switching Power Suplay, PC motherboard, Cordless Telephone, dan perangkat komunikasi. LM393 berupa IC DIP (Dual In-line Package) 8 pin. Adapun konfigurasi pin pada IC LM393 dapat dilihat pada Gambar berikut.

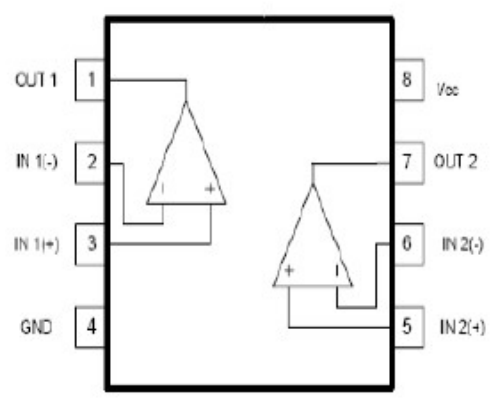

Gambar 4. Konfigurasi Pin LM393 [11] 
4. Sensor Logam Induktif

Sensor proximity yang berdasar atas perubahan induktansi karena adanya benda logam adalah salah satu yang paling banyak digunakan di industri. Efek dari sensor yang berada di dekat bahan ferromagnetic menyebabkan perubahan pada posisi garis fluks magnet permanen. Dalam kondisi statis tidak ada gerakan dari garis fluks akan menyebabkan tidak ada arus yang diinduksi dalam kumparan. Polaritas tegangan dari sensor tergantung pada apakah objek tersebut memasuki atau meniggalkan medan magnet [12].

Adapun sensor logam induktif yang akan digunakan pada penelitian ini adalah sensor logam induktif ROKO SN04. Mempunyai 3 kabel yang terdiri dari 2 pin catu daya (positif dan negatif) serta 1 pin (hitam) untuk keperluan komunikasi [13].

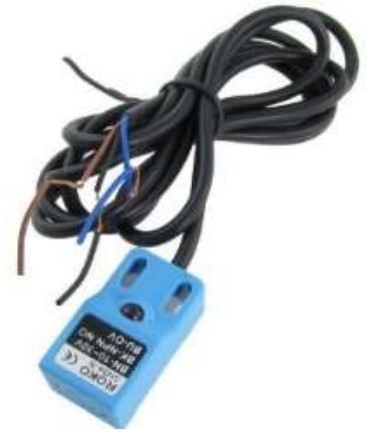

Gambar 5. Sensor Logam Roko SN04

spesifikasi sensor metal Roko SN04:
a. Jarak deteksi
: 0mm hingga $4 \mathrm{~mm}$.
b. Tegangan kerja : $10-30 \mathrm{~V} D C$.
c. Suhu kerja : $-25^{\circ} \mathrm{C}$ hingga $70^{\circ} \mathrm{C}$.
d. Bobot : 60 gram.
e. Ukuran : $34 \mathrm{~mm} \times 18 \mathrm{~mm} \times 14 \mathrm{~mm}$.

\section{Modul Sensor Cahaya LDR (Light Dependent Resistor)}

$L D R$ atau sensor cahaya adalah salah satu jenis resistor yang dapat mengalami perubahan resistansi apabila mengalami perubahan penerimaan cahaya. Besarnya nilai hambatan pada sensor cahaya $L D R$ tergantung pada besar kecilnya cahaya yang diterima oleh $L D R$ itu sendiri. $L D R$ sering disebut dengan alat atau sensor yang berupa resistor yang peka terhadap cahaya [6].

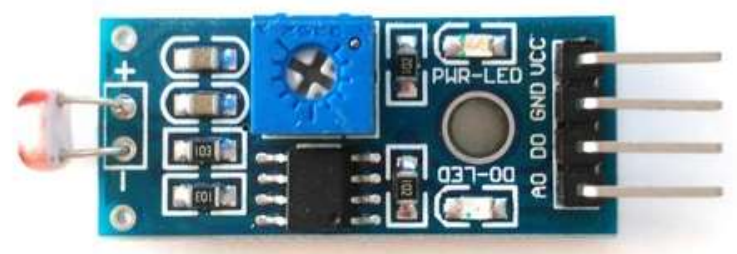

Gambar 6. Modul Sensor Cahaya

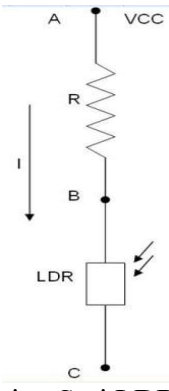

Gambar 7. Rangkaian Seri LDR dan Resistor [11]

$\begin{array}{ll}\mathrm{V}_{\mathrm{CC}} & =\mathrm{V}_{\mathrm{AB}}+\mathrm{V}_{\mathrm{BC}} \\ \mathrm{V}_{\mathrm{CC}} & =\mathrm{V}_{\mathrm{R}}+\mathrm{V}_{\mathrm{LDR}}\end{array}$

$\mathrm{V}_{\mathrm{CC}} \quad=\mathrm{I} \times \mathrm{R}_{\text {total }}$

$\mathrm{R}_{\text {total }}=\mathrm{R}+\mathrm{R}_{\mathrm{LDR}}$

I $\quad=V_{\mathrm{CC}} / \mathrm{R}_{\text {total }}$

$\mathrm{V}_{\mathrm{BB}} \quad=\mathrm{V}_{\mathrm{CC}}-\mathrm{V}_{\mathrm{AB}}$

$=\left(\mathrm{I} \times \mathrm{R}_{\text {total }}\right)-(\mathrm{I} \times \mathrm{R})$

$=\mathrm{I} \times\left(\mathrm{R}_{\text {total }}-\mathrm{R}\right)$

$=\mathrm{I} \times \mathrm{R}_{\mathrm{LDR}}$

6. Motor Servo

Motor servo adalah sebuah motor $D C$ yang dilengkapi rangkaian kendali dengan sistem closed feedback yang terintegrasi dalam motor tersebut. Pada motor servo posisi putaran sumbu (axis) dari motor akan diinformasikan kembali ke rangkaian kontrol yang ada di dalam motor servo [14].

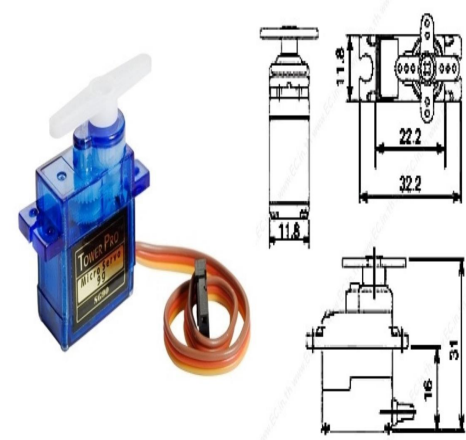

Gambar 8. Servo TowerPro SG90 [15]

7. LASER (Light Amplification By Stimulated Emission Of Radiation)

Dioda laser adalah sejenis laser di mana media aktifnya sebuah semikonduktor persimpangan $p-n$ yang mirip dengan dioda pemancar cahaya. Prinsip kerja dioda laser yaitu melalui sirkuit dari rangkaian elektronika, yang terdiri dari jenis $\mathrm{p}$ dan $\mathrm{n}$. Pada laser sering dihasilkan 2 tegangan, yaitu:

1. Biased forward, arus dihasilkan searah dengan nilai 0,707 untuk pembagian tegangan puncak, bentuk gelombang di atas $(+)$. 
2. Backforward biased, merupakan tegangan berbalik yang dapat merusak suatu komponen elektronika [11].

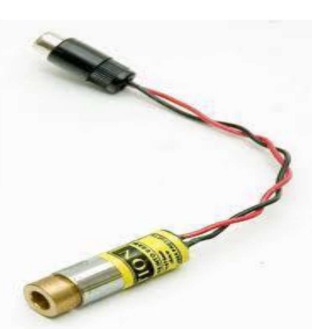

Gambar 9. Laser [11]

8. Relay

Relay adalah komponen elektronika berupa saklar elektronik yang digerakkan oleh arus listrik. Secara prinsip, relay merupakan tuas saklar dengan lilitan kawat pada batang besi (solenoid) di dekatnya. Ketika solenoid dialiri arus listrik, tuas akan tertarik karena adanya gaya magnet yang terjadi pada solenoid sehingga kontak saklar akan menutup. Pada saat arus dihentikan, gaya magnet akan hilang, tuas akan kembali ke posisi semula dan kontak saklar kembali terbuka [4].

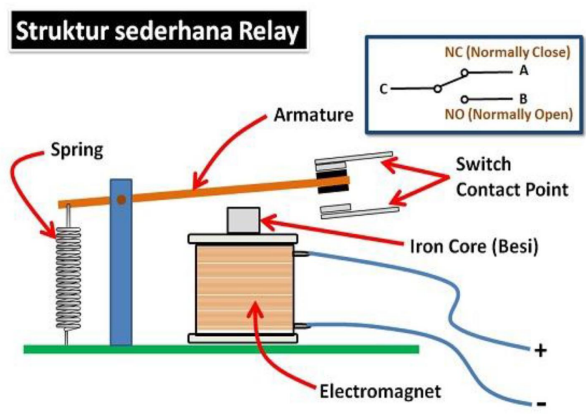

Gambar 10. Struktur Sederhana Relay [17]

Pada saat tidak dialiri arus listrik, Armature akan kembali lagi ke posisi Awal (NC). Coil yang digunakan oleh Relay untuk menarik Contact Poin ke Posisi Close pada umumnya hanya membutuhkan arus listrik relatif kecil [8].

\section{METODE}

\section{A. Konsep Rancangan}

Langkah awal dalam perancangan alat adalah menentukan konsep dari rancangan alat yang akan dibuat. Gambar 9 adalah blok diagram yang menggambarkan konsep dasar dari alat yang akan dirancang.

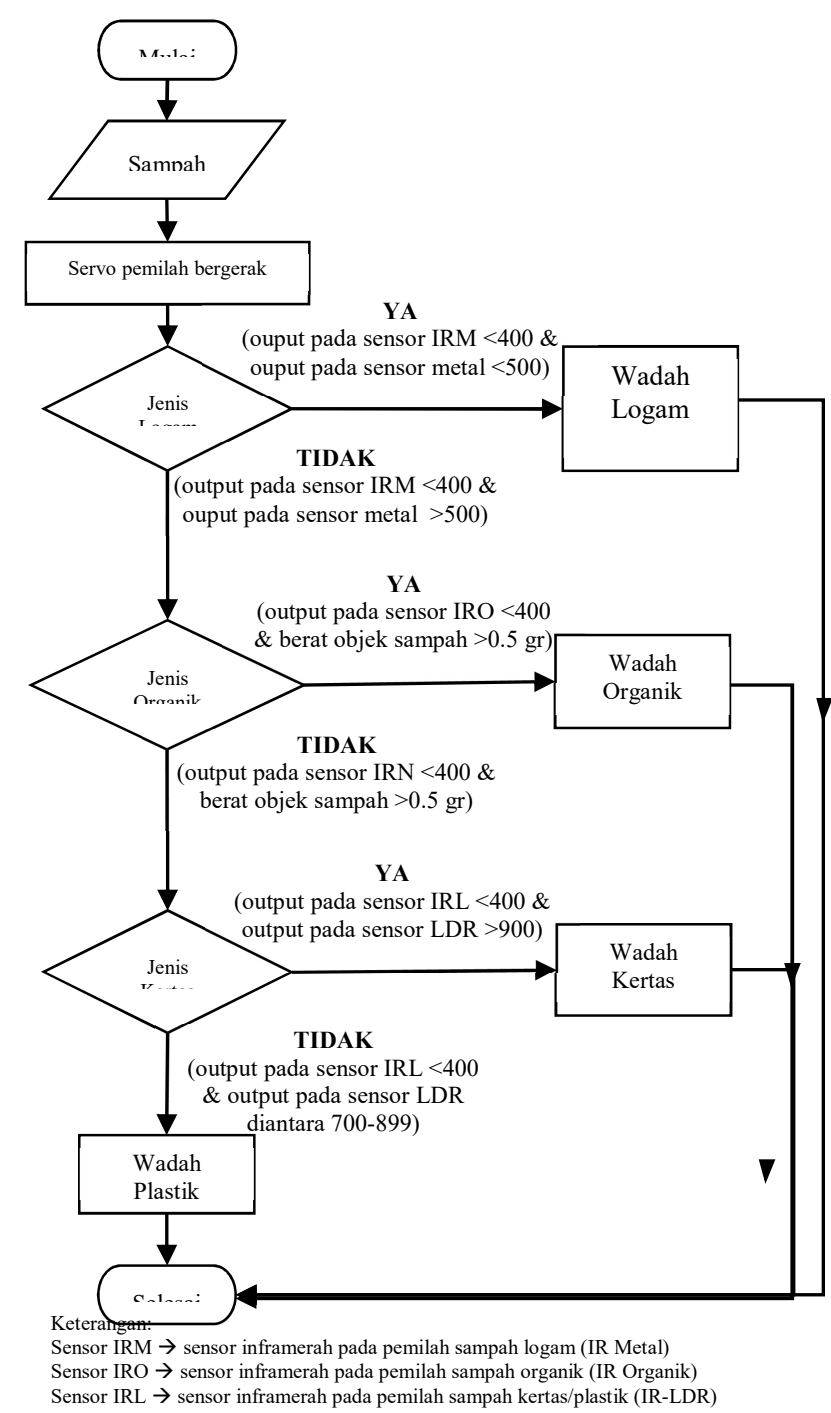

Gambar 11. Diagram Blok Sistem

\section{B. Perancangan Alat}

Alat akan dirancang berdasarkan pada kebutuhan sistem. Adapun perancangan alat pemilah sampah otomatis akan terdiri dari:

1. Perancangan pendeteksi objek sampah

2. Perancangan pemilah logam.

3. Perancangan pemilah organik.

4. Perancangan pemilah kertas.

5. Perancangan pemilah plastik.

Untuk perancangan perangkat lunak meliputi inisialisasi program pada mikrokontroler, inisialisasi sensor, dan inisialisasi alat pendukung tambahan.

1. Perancangan pendeteksi keberadaan sampah

Bagian ini berfungsi untuk mengindikasikan bahwa terdapat sampah yang harus diproses oleh alat. Terdiri dari sensor jarak infra merah dan servo. 
2. Perancangan pemilah logam

Bagian ini akan berfungsi sebagai pemilah sampah yang mengandung logam. Terdiri dari sensor logam dan servo.

\section{Perancangan pemilah organik}

Bagian ini akan berfungsi sebagai pemilah sampah organik dengan menggunakan metode perbedaan berat sampah. Terdiri dari sensor infra merah, servo, dan kipas pendorong.

\section{Perancangan pemilah kertas}

Bagian ini akan berfungsi sebagai pemilah sampah kertas dengan memanfaatkan metode perbedaan pemantulan cahaya oleh kertas. Kertas cenderung memantulkan cahaya yang mengenainya. Terdiri dari sensor infra merah, sensor cahaya, servo, dan laser.

\section{Perancangan pemilah plastik}

Bagian ini akan berfungsi sebagai pemilah sampah plastik dengan memanfaatkan metode perbedaan pemantulan cahaya. Terdiri dari sensor infra merah, sensor cahaya, servo, dan laser. Bagian pemilah plastik merupakan satu tempat yang sama pada bagian pemilah kertas.

\section{Rangkaian Sensor dengan Arduino UNO}

Hubungan rangkaian sensor dengan arduino UNO dapat dilihat pada Gambar berikut.

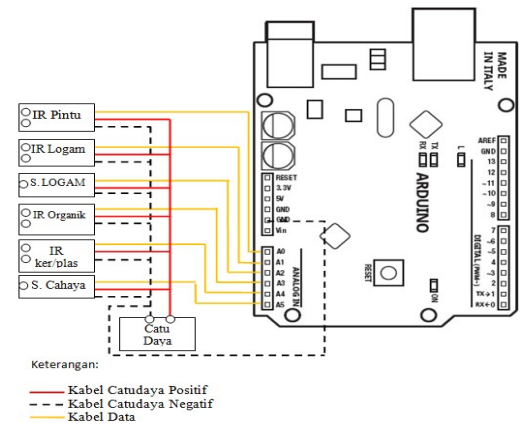

Gambar 12. Rangkaian Sensor dengan Arduino UNO

7. Rangkaian Sensor dengan Arduino UNO Hubungan rangkaian sensor dengan arduino UNO dapat dilihat pada Gambar berikut.

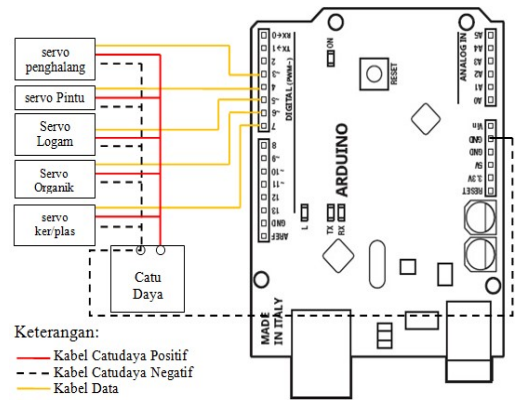

Gambar 13. Rangkaian Servo dengan Arduino UNO

\section{Perancangan Alat (software)}

Perancangan perangkat lunak bertujuan untuk menetapkan nilai-nilai dan fungsi pada penulisan program sehingga tujuan dari perancangan perangkat keras dapat tercapai.

\section{Software pemograman}

Mikrokontroler arduino memiliki memori yang terbatas, sehingga mempunyai kemampuan memproses data yang terbatas juga. Input analog pada mikrokontroler arduino uno hanya mampu membaca nilai digital sebesar 10 bit, sehingga arduino uno hanya mampu mengkonversi data digital ke data analog sebesar $1024\left(2^{\wedge} 10\right)$. Besaran konversi akan bernilai mulai dari 0 hingga 1023 . Nilai 0 berarti 0 volt, sedangkan nilai 1023 berarti 5 volt. Sehingga setiap cacahan akan memiliki nilai 5/1023 volt.

\section{Inisialisasi Sensor}

Nilai yang dihasilkan oleh sensor (tegangan) akan diproses oleh arduino $(A D C)$ sehingga dapat ditampilkan pada bagian serial monitor. Adapun kalibrasi yang perlu dilakukan antara lain adalah:

a. Sensor pendeteksi keberadaan objek sampah

Nilai sensor IR harus lebih dari 200 dalam keadaan tidak mendeteksi objek (nilai maksimal adalah 1023 dalam mikrokontroler arduino). jika sensor menghasilkan keluaran yang lebih kecil dari 200, maka sensor dianggap mendeteksi adanya keberadaan objek sampah. Berikut merupakan potongan kode program kerja sensor $I R 1$ sebagai sensor pendeteksi objek sampah.

b. Sensor pemilah sampah logam

Untuk inisialisasi sensor $I R$ bagian pemilah sampah logam, nilai awal dari sensor harus lebih besar dari 400, sensor dianggap mendeteksi benda jika menghasilkan nilai keluaran lebih kecil dari 400. Untuk inisialisasi sensor logam, nilai awal sensor logam harus lebih besar dari 500, sensor dianggap mendeteksi benda berjenis logam jika menghasilkan keluaran lebih kecil dari 500.

c. Sensor pemilah sampah organik

Sebagai pendeteksi keberadaan sampah organik, hanya digunakan sensor $I R$. Nilai awal dari sensor harus lebih dari 400, sensor dianggap mendeteksi benda jika menghasilkan nilai keluaran lebih kecil dari 400.

d. Sensor pemilah sampah kertas dan pemilah sampah plastik

Untuk mendeteksi objek sampah dengan jenis kertas ataupun jenis plastik, digunakan 2 buah sensor yakni sensor IR dan sensor cahaya. 
Inisialisasi sensor $I R$ pemilah sampah kertas dan pemilah sampah plastik sama seperti pada sensor $I R$ logam. Nilai awal dari sensor harus lebih dari 400, sensor dianggap mendeteksi benda jika menghasilkan nilai keluaran lebih kecil dari 400. Sedangkan untuk inisialisasi sensor cahaya, nilai awal sensor cahaya harus lebih kecil dari 700, sensor akan dianggap mendeteksi benda berjenis kertas jika menghasilkan keluaran lebih besar dari 900, kemudian sensor akan dianggap mendeteksi benda berjenis plastik jika menghasilkan keluaran dengan rentang nilai antara 700 hingga 899.

\section{Inisialisasi Alat Pendukung}

Inisialisasi alat pendukung bertujuan untuk mendeklarasikan posisi awal alat saat program mulai berjalan. Hal ini diperlukan agar tidak terjadi kesalahan fungsi alat dan sensor.

\section{Servo}

Servo merupakan motor bergigi yang digunakan untuk mengerakkan bagian-bagian pemilah. Dikarenakan penggunaan servo dalam jumlah yang banyak, maka masing-masing servo harus diatur posisi awalnya serta posisi servo saat sensor memberikan keluaran. Pengaturan posisi servo dapat dijelaskan adalah:
a. Servo penghalang
Posisi awal $90^{\circ}$, posisi deteksi objek $50^{\circ}$.
b. Servo pintu
Posisi awal $65^{\circ}$, posisi deteksi objek $140^{\circ}$.
c. Servo logam
Posisi awal $130^{\circ}$, posisi deteksi logam 178, posisi deteksi non-logam $70^{\circ}$.
d. Servo organik
Posisi awal $180^{\circ}$, posisi deteksi organik $90^{\circ}$.
e. Servo kertas dan plastik
Posisi awal $107^{\circ}$, posisi deteksi kertas $180^{\circ}$, posisi deteksi plastik $0^{\circ}$.

\section{Alat tambahan}

Selain penggunaan servo, dibutuhkan alat tambahan yang dapat menjalankan fungsi tertentu. Alat tambahan merupakan alat pendukung yang digunakan agar tujuan suatu aksi dapat tercapai.

Adapun alat tambahan yang digunakan dalam tempat pemilah sampah otomatis adalah adalah:

a. Relay

Relay digunakan untuk mengendalikan keadaan kipas. Posisi awal relay adalah normally open (NO), posisi relay ketika sensor mendeteksi adanya objek selama 2 detik harus berubah ke keadaan normally close (NC).

b. Kipas

Kipas akan dikendalikan oleh relay. Kipas harus berada dalam keadaan mati saat awal dan harus hidup ketika sensor mendeteksi objek selama 2 detik.

\section{c. Modul laser}

Laser harus tetap berada dalam keadaan hidup dimulai saat program telah berjalan.

\section{HASIL DAN PEMBAHASAN}

Pengujian alat dilakukan dengan cara memasukkan objek sampah secara langsung. Percobaan dilakukan dengan 2 jenis sampah, yakni sampah yang sejenis dan sampah yang dicampur. Masing-masing percobaan dilakukan sebanyak 15 kali untuk mendapatkan nilai rata-ratanya.

Setelah melakukan perancangan dan pengujian alat, akan didapatkan hasil pengujian berupa data kuantitatif. Hasil perancangan berupa alat dapat dilihat pada Gambar 14.
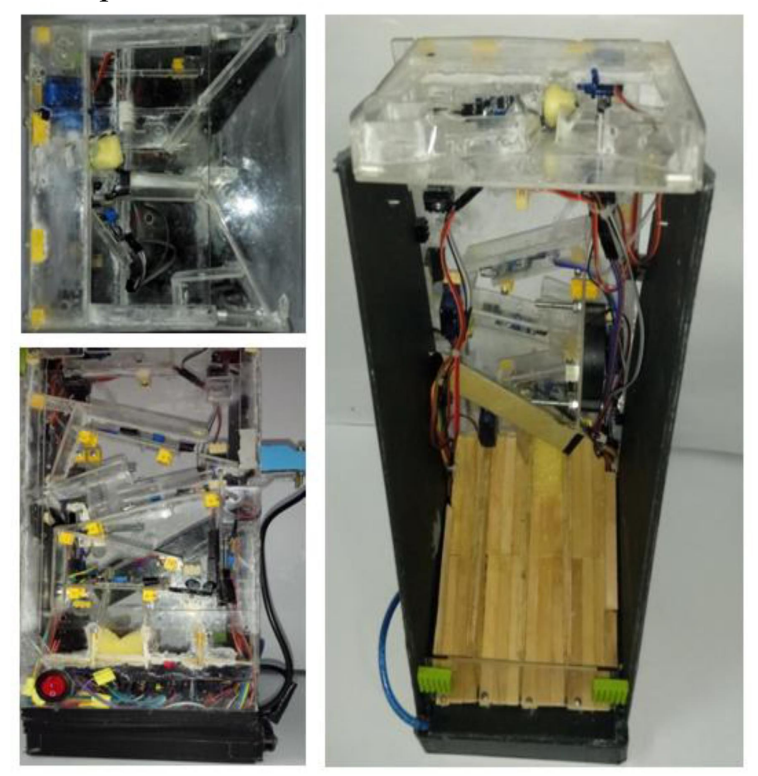

Gambar 14. Hasil Perancangan

\section{A. Hasil Pengujian}

Hasil pengujian alat menunjukkan sensor yang digunakan telah mampu membedakan jenis sampah logam, organik, kertas, dan plastik. Adapun hasil pengujian alat dapat dilihat pada masing-masing tabel hasil pengujian dibawah ini. Tabel 1 menunjukkan hasil pengujian untuk sampah sejenis.

Tabel 1. Hasil Pengujian Sampah Sejenis

\begin{tabular}{|c|c|c|c|c|c|c|}
\hline \multirow{2}{*}{ JENIS } & \multicolumn{5}{|c|}{ Kesimpulan (Sejenis) } & \multirow{2}{*}{$\begin{array}{c}\text { Keakura - } \\
\text { tan (\%) }\end{array}$} \\
\cline { 2 - 7 } & Kertas & Plastik & Logam & Organik & $\begin{array}{c}\text { Gagal } \\
\text { (Tersangkut) }\end{array}$ \\
\hline Logam & 0 & 0 & $\mathbf{1 4 7}$ & 0 & 3 & $\mathbf{9 8 \%}$ \\
\hline Organik & 26 & 56 & 1 & $\mathbf{4 0}$ & 27 & $\mathbf{2 6 . 6 7 \%}$ \\
\hline Kertas & $\mathbf{4 8}$ & 51 & 0 & 25 & 26 & $\mathbf{3 2 \%}$ \\
\hline Plastik & 34 & $\mathbf{8 7}$ & 0 & 11 & 18 & $\mathbf{5 8 \%}$ \\
\hline \multicolumn{7}{|c|}{ Total } \\
\hline
\end{tabular}


Tabel 2 menunjukkan hasil pengujian untuk sampah campuran.

Tabel 2. Hasil Pengujian Sampah Campuran

\begin{tabular}{|c|c|c|c|c|c|c|}
\hline \multirow{2}{*}{ JENIS } & \multicolumn{5}{|c|}{ Kesimpulan (Campuran) } & \multirow{2}{*}{$\begin{array}{c}\text { Keakura - } \\
\text { tan (\%) }\end{array}$} \\
\cline { 2 - 6 } & Kertas & Plastik & Logam & Organik & $\begin{array}{c}\text { Gagal } \\
\text { (Tersangkut) }\end{array}$ & $\mathbf{9 4 . 6 7 \%}$ \\
\hline Logam & 2 & 4 & $\mathbf{1 4 2}$ & 2 & 0 & $\mathbf{2 8 \%}$ \\
\hline Organik & 28 & 40 & 22 & $\mathbf{4 2}$ & 18 & $\mathbf{1 2 \%}$ \\
\hline Kertas & $\mathbf{1 8}$ & 55 & 28 & 39 & 10 & $\mathbf{4 1 . 3 \%}$ \\
\hline Plastik & 34 & $\mathbf{6 2}$ & 24 & 20 & 10 & $\mathbf{4 4 \%}$ \\
\hline \multicolumn{7}{|c|}{ Total } \\
\hline
\end{tabular}

Tabel 3 yang menunjukkan hasil rata-rata untuk kedua jenis pengujian.

tabel 3. Hasil Pengujian Sampah Campuran

\begin{tabular}{|c|c|c|c|c|c|c|}
\hline \multirow{2}{*}{ JENIS } & \multicolumn{5}{|c|}{ Kesimpulan (Total) } & \multirow{2}{*}{$\begin{array}{c}\text { Keakura - } \\
\text { tan (\%) }\end{array}$} \\
\cline { 2 - 6 } & Kertas & Plastik & Logam & Organik & $\begin{array}{c}\text { Gagal } \\
\text { (Tersangkut) }\end{array}$ & $\mathbf{9 6 . 3 \%}$ \\
\hline Logam & 2 & 4 & $\mathbf{2 8 9}$ & 2 & 3 & $\mathbf{2 7 . 3 \%}$ \\
\hline Organik & 54 & 96 & 23 & $\mathbf{8 2}$ & 45 & $\mathbf{2 2 \%}$ \\
\hline Kertas & $\mathbf{6 6}$ & 106 & 28 & 64 & 36 & $\mathbf{4 9 . 6 7 \%}$ \\
\hline Plastik & 68 & $\mathbf{1 4 9}$ & 24 & 31 & 28 & $\mathbf{4 8 . 8 \%}$ \\
\hline \multicolumn{7}{|c|}{ Total } \\
\hline
\end{tabular}

Dari hasil pengujian, dapat dilihat bahwa masih terdapat kesalahan berupa sampah tersangkut dan kesalahan pendeteksian oleh sensor.

\section{B. Pembahasan}

Alat pemilah sampah otomatis menggunakan beberapa metode dan sensor untuk membedakan jenis sampah. Metode dan sensor yang digunakan akan mempengaruhi hasil pemilahan sampah. Diperlukan metode dan sensor yang tepat sesuai karakteristik sampah yang akan dideteksi sehingga sampah dapat dipilah. Adapun keefektifan metode dan sensor yang digunakan dapat dibahas adalah:

1. Pemilah sampah logam

Sensor logam yang digunakan dapat mendeteksi benda berbahan logam secara baik. Metode yang digunakan adalah penempatan sensor logam pada bagian awal alat memberikan hasil yang baik. Posisi sensor dapat dilihat pada Gambar berikut.

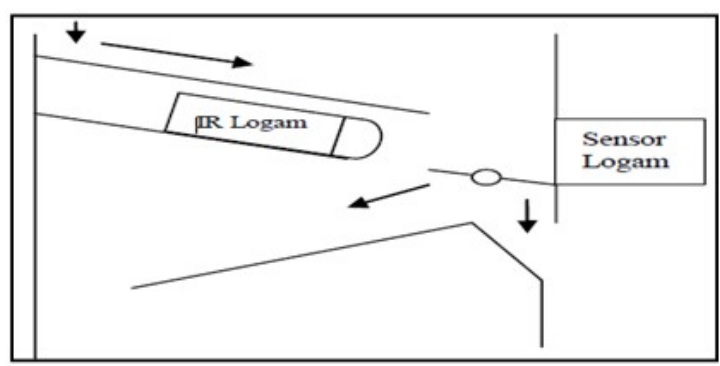

Gambar 15. Posisi Sensor Logam
2. Pemilahan sampah organik

Sensor infra merah yang digunakan dapat mendeteksi keberadaan sampah. Namun metode mendeteksi sampah organik dengan cara perbedaan berat sampah organik dengan sampah kertas dan sampah plastik kurang tepat. Seringkali sistem gagal memilah sampah organik. Metode dengan penggunaan kipas dapat dilihat pada Gambar berikut.

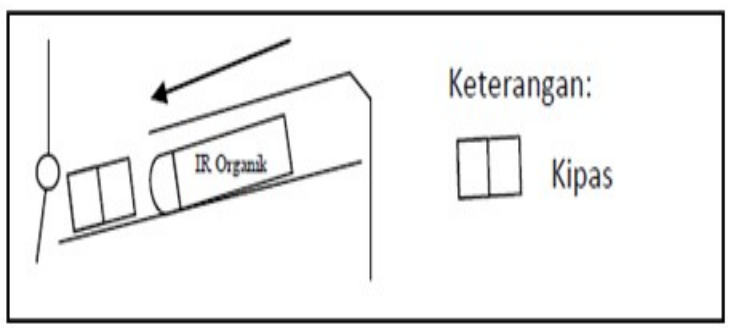

Gambar 16. Metode Pemisahan Sampah Organik

3. Pemilahan sampah kertas

Sensor infra merah telah mampu mendeteksi keberadaan objek. Namun penggunaan sensor cahaya masih kurang optimal. Perbedaan ukuran kertas dan posisi jatuh kertas yang tidak sesuai mempengaruhi hasil pendeteksian sensor cahaya. Metode memilah kertas dengan plastik menggunakan perbedaan cahaya masih kurang optimal. Metode menggunakan cahaya untuk membedakan sampah kertas dengan sampah plastik dapat dilihat pada Gambar berikut.

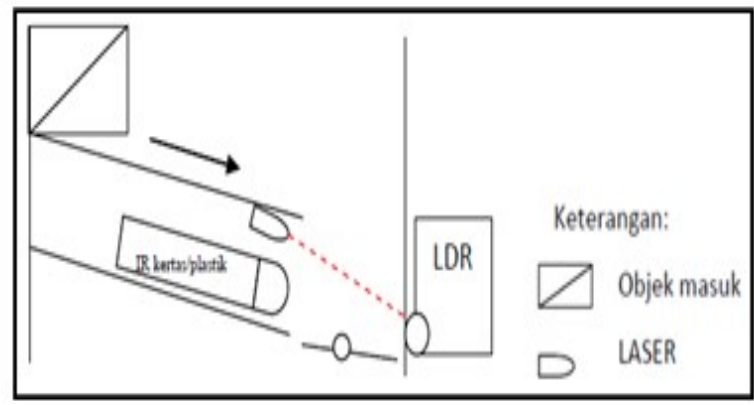

Gambar 17. Metode Cahaya Untuk Membedakan kertas dengan Plastik

4. Pemilahan sampah plastik

Sensor infra merah telah mampu mendeteksi keberadaan objek. Penggunaan sensor cahaya yang disinkronkan dengan sensor infra merah mampu memberikan hasil pendeteksian yang lebih baik daripada hasil sampah kertas. Sensor cahaya yang digunakan adalah modul sensor LDR (light dependent resistor). $L D R$ akan sangat resisten jika tidak terkena cahaya, sebaliknya nilai resistansi $L D R$ akan sangat rendah bila terkena cahaya yang sangat terang. 


\section{KESIMPULAN}

Hasil percobaan pada prototype alat pemilah sampah otomatsi menunjukkan bahwa alat yang dirancang telah mampu membedakan jenis sampah berdasarkan bahan sampah. Pemilahan pada bagian logam menghasilkan keakuratan terbaik berkat penggunaan sensor logam. Namun pemilahan pada bagian lain tidak menghasilkan keakuratan yang baik. Masih terdapat kesalahan pendeteksian dan kesalahan akibat tersangkutnya sampah di dalam alat.

Beberapa saran untuk pengembangan pada penelitian selanjutnya Perancangan desain alat pada bagian pintu yang lebih efektif agar sampah dapat masuk secara lancar. Perancangan sensor organik yang dapat digunakan untuk mendeteksi sampah organik secara langsung dengan pemanfaatan sensor gas dan sensor lain.

Merancang alat pemilah sampah yang mampu mendeteksi jenis sampah yang mempunyai ukuran beragam (tidak standart) dengan meningkatkan daya deteksi sensor dengan pemakaian sensor skala industri ataupun menggunakan sinkronisasi sensor (lebih dari satu buah).

\section{DAFTAR PUSTAKA}

[1] F. Restu, "Rekayasa Mesin Pemilah dan Penghancur Sampah Otomatis Dengan Sistem Kendali Kontrol Sederhana Pada Skala Internal Politeknik Negeri Batam," Jurnal integrasi, ISSN: 2085-3858, 2013.

[2] M. H. Russel, M. H. Chowdhury, Md. S. N. Uddin, A. Newaz, Md. M. M. Talukder, "Development Of Automatic Smart Waste Sorter Machine," International Conference on Mechanical, Industrial and Materials Engineering 2013 (ICMIME2013) 1-3 November, 2013, RUET, Rajshahi, Bangladesh. Paper Id: AM-012, 2013.

[3] S. Aslamia, "Robot Pendeteksi Manusia Sebagai Sistem Keamanan Ruangan Menggunakan Sensor PIR Dengan Media Komunikasi XBEE Berbasis Arduino Leonardo", Politeknik Negeri Sriwijaya Palembang, 2015.

[4] V. Masinambow, "Pengendali Saklar Listrik Melalui Ponsel pintar Android," e-journal Teknik Elektro dan Komputer (2014), ISSN 2301-8402, 2014.
[5] S. Rahmawati, "Simulasi Membuka, Menutup Pintu dan Menghidupkan Mesin Mobil Menggunakan Android," Politeknik Negeri Sriwijaya Palembang, 2015.

[6] S. J. Sokop, "Trainer Periferal Antarmuka Berbasis Mikrokontroler Arduino Uno," EJournal Teknik Elektro dan Komputer vol.5 no.3 (2016), ISSN : 2301-8402, 2016.

[7] D. Wheat, Arduino Internals, New York: Apress, 2011

[8] D. T. Saputra, "Aplikasi Sensor Ultrasonik HCSR04 Pada Sistem Kendali Valve Sebagai Penyalur Air Dengan Akses Control RFID Berbasis Arduino Uno," Politeknik Negeri Sriwijaya Palembang, 2015

[9] G. Felix, J. D. Ning, "Enchanced Bank Vault (Strong Room) Security System Design," International Journal of Science and Research (IJSR), ISSN (Online): 2319-7064, 2015.

[10]F. Y. Atmaja, "Otomatisasi Kran Dan Penampung Air Pada Tempat Wudhu Berbasis Mikrokontroler", Universitas Sebelas Maret, 2010.

[11]E. Tuluk, "Implementasi Alat Pengusir Hama Burung Di Area Persawahan Dengan Menggunakan Gelombang Ultrasonik Berbasis Mikrokontroler ATMEGA168," Vol.VII Nomor 21 Nopember 2012 - Jurnal Teknologi Informasi, ISSN : 1907-2430, 2012.

[12] R. M. K. Wijaya,"Studi Penggunaan Proximity Sebagai Saklar Pada Alat Penomoran Pupuk Urea Kantong Di PT. Pupuk Sriwidjaja,' Politeknik Negeri Sriwijaya Palembang, 2014.

[13] M. G. Toto, G. A. Mutiara, dan G. I. Hapsari, "Memperluas Jangkauan AR Drone 2.0 Menggunakan Wifi Extender," e-Proceeding of Applied Science: Vol.1, No.2 Agustus 2015, ISSN : 2442-5826, 2015.

[14]Harahap, U., Pasaribu, F. I., Kontrol, I. S., Tutup, B., Pada, V., Pemanasan, P., \& Jaket, A. (2018). Journal of Electrical and System Control Engineering Sistem Kontrol Buka Tutup Valve Pada Proses Pemanasan Air Jaket, Vol.1, No.2 Agustus 2018, ISSN : 2549-6298.

[15] Towerpro. Datasheet Servo SG9 [online] Tersedia: www.towerpro.tw/ product, 16 Juli 2017

[16] Maxwell. Datasheet SN04. http://www.electronicaestudio.com/docs/SHT- 170.pdf. 16 Juli 2017. 